\title{
The Issues Japanese Higher Education Face in the Digital Age-Are Japanese Universities to Blame for the Slow Progress towards an Information-based Society?
}

\author{
Miho Funamori ${ }^{*}$
}

\begin{abstract}
A quarter of a century has passed since the Internet was opened to general use. The impact of the Internet, which was initially moderate, is gradually taking shape. The Fourth Industrial Revolution is materializing with the advent of the Internet of Things and artificial intelligence. At the same time, higher education is in a period of drastic reform, driven by the globalization, marketization, and massification of higher education. However, adapting to the digital age has not been a priority, and as the turmoil of reforms is settling down, the gaps among universities in terms of adapting to the digital age have become apparent. Japanese universities are among the adaptation laggards. They have also drawn criticism for not being effective enough in producing skilled IT engineers and fostering the development of IT-related startups. But are Japanese universities to blame for the shortcomings of the Japanese IT industry?

This paper analyzes the slow progress towards an information-based society in Japan by first comparing the measures taken by universities at the beginning of the digital age and the criticism Japanese universities have drawn. It then discusses the issues Japan is facing in transitioning to an information-based society and the contributions Japanese universities could make.
\end{abstract}

Keywords: Digital age, higher education, information-based society, university reform.

\section{Introduction}

A quarter of a century has passed since the Internet was opened to general use. In the early 1990s, when Internet use started spreading, the change was fairly moderate - transactions were transferred from the physical space to the digital sphere. Then, as information accumulated in the digital sphere and platforms providing various services became common, Internet traffic grew. New means of communication such as social networking and "wisdom of the crowd" querying became prevalent [1][2]. Mobile devices such as the smartphones also contributed to the expansion of Internet usage. We now live in a cyber-physical world where communications and activities are merged across the cyber and physical spaces. In addition, the Fourth Industrial

* National Institute of Informatics, Tokyo, Japan 
Revolution is materializing with the advent of the Internet of Things (IoT) and artificial intelligence (AI), enabling decision-making beyond human capabilities.

Higher education around the world transitioned into the digital age alongside the proliferation of the Internet. In general, universities were at the forefront of this transition as most of the related technologies were invented at universities. However, it was mainly the science-related departments that were the leaders. The other departments trailed behind, along with the general public. As the use of the Internet and personal computers became widespread, research and educational resources started being created digitally from the beginning and shared with ease over the Internet. Journal articles became electronically available and searchable through the Internet. Moreover, it became possible to automatically calculate the impact factors of academic journals and the citation counts of journal articles, changing how researchers were being evaluated. Online learning materials became available and are now widely used in a blended learning format. Information systems for university business use, such as accounting and human resource management, were developed and introduced. Courses came to be managed through learning management systems. Computer science departments offered computer engineering training while other departments offered computer literacy training.

This transition at universities was not specifically planned except in the related areas such as IT centers. Moreover, higher education worldwide has been in a state of drastic reform since the 1990s.

An eminent example of university reform is the Bologna Process, which is aimed at harmonizing the higher education systems within the European Union (EU) in order to address the globalization trend. Many other universities around the world are also implementing reform measures. Many universities are restructuring their governance structure from collegial consensus making to agile university management. Marketization has moved into the higher education sphere, and universities are managing their operations more like corporate entities [3]. The shift towards a knowledge economy is driving governments to strive for greater attainment rates in higher education, which is transforming higher education from the elite's restricted access to the masses' universal access. This massification of higher education, however, has led to shortfalls in higher education budgets, which, in turn, has pushed universities towards stringent management practices. Massification is also resulting in a more diverse student body. This diversity has increased the need for individualized student care as students are no longer able to follow the one-size-fits-all one-way lecture style [4]. The introduction of world university rankings has expanded competition from domestic competition to worldwide competition. The world's leading universities now have to compete on a global stage.

In the face of these drastic reforms, it is no wonder that most universities did not focus on the need to adapt to the digital age. Adapting to the globalization, marketization, and massification of higher education has been by far the most pressing issue. However, as the turmoil of higher education reforms settles down, the gaps among universities in terms of adapting to the digital age have become apparent. Universities in the U.S. are among the most advanced in this regards. IT centers at public universities in the U.S. are generally staffed with more than 100 professionals providing Internet network infrastructures and academic services. In contrast, the IT centers at Japanese public and private universities are generally understaffed and thus provide a minimum level of services. The information systems are mostly unsophisticated and difficult to use. Learning management systems are used for only a small number of courses. On top of this, Japanese universities are criticized for not producing a sufficient number of skilled IT engineers and for not promoting the start-up of IT companies.

What accounts for these shortcomings of Japan in the digital age? Japan has been a leader in 
electronics since the 1980s, and the Japanese government has been heavily investing in policy measures to promote the transition to an information-based society. Why is Japan lagging behind other developed countries? Is there still a chance to close the gap? What should be done to do so?

This paper analyzes the slow progress towards an information-based society in Japan by first comparing the measures taken by universities at the beginning of the digital age and the criticism Japanese universities have drawn. It then discusses the issues Japan is facing in transitioning to an information-based society and contributions Japanese universities could make.

\section{Measures taken by Japanese universities at the beginning of digital age}

This section provides an overview of the measures taken by Japanese higher education during the period when computers and the Internet were introduced. The measures examined were selected from among the policies successively developed by the Japanese government.

\subsection{Forming departments in computer sciences}

Measures to adapt to the digital age started in the 1940s and 50s with the development of computers and research in related areas. Even though the processing power of computers was highly welcomed, there was initial skepticism about whether a discipline focusing on computers could be formed. However, as computers became available not only for numerical processing but also for various forms of information processing, the research field broadened and attracted researchers with various interests. In the 1960s, computer science emerged as an academic discipline, and universities began to establish relevant departments.

In the early days of computing in Japan, workshops and training sessions on the use of computers and information processing were held by individual academics who were excited about this field. Subsequently, when various theories on an "information society" were proposed in the 1970s, the government took the initiative in propelling the transition to an information-based society [5][6][7]. The Japanese government forecast the demand for computer engineers and established computer science departments accordingly [8]. In the 1980s, when microelectronics and VLSI (very large scale integration circuits) rapidly advanced, industry experienced a serious shortage of computer engineers. Universities could not keep up with demand, so vocational schools were established to help meet the demand.

Although these measures increased the number of computer engineers, industry required quality engineers. Universities were criticized for not producing computer engineers with the required practical skills. Demand increased for computer engineers with a better understanding of the needs of business and the business information systems being deployed. The Japanese government took measures to train computer engineers through university-industry linkages. IT companies such as Microsoft and Google are now making similar claims and attempting to develop the needed workforce themselves.

\subsection{Introduction of information literacy education}

Measures to raise the information literacy of the general public were also taken. The National Forum on Information Literacy defines information literacy as "the ability to know when there is a need for information, to be able to identify, locate, evaluate, and effectively use that 
information for the issue or problem at hand" [9]. Whereas information literacy is the ability to use information in general, computer literacy, or digital literacy, is defined as "the ability to use computers and related technology efficiently, with a range of skills covering levels from elementary use to programming and advanced problem solving." When computers were first introduced for general use, skills in their use were in demand, and universities began to offer courses and training sessions for general students on how to use them [10]. In the late 1980s, several research universities in Japan began to offer information processing courses. Other universities followed suit in the 1990s. The focus was on the use of personal computers and not on information processing, such as computer programming and performing numerical calculations.

By 2000 , more than $30 \%$ of the population owned a computer, and after 2006 , when students who had taken compulsory "information" courses began to enter universities, many universities discarded computer literacy education and switched to information literacy education. The courses were built around "locating information," "processing information," and "expressing through information" [11]. These courses are now commonly provided as freshman seminars as part of academic literacy education.

\subsection{Establishing IT infrastructure}

Along with the development of human resources, IT infrastructures were deployed at universities to support the growing use of personal computers and information networks. The computers were initially shared among labs, and it was some time before personal computers were installed in each lab. Educational computer centers were established to serve students, and computers for university business use were established on a larger scale to serve management.

Information networks were established on both a nationwide scale and a campus scale. Japan has a special institute - the National Institute of Informatics (formerly the National Center for Science Information Systems) - that provides information networks and services exclusively for academic institutions. Academic institutions use public information networks only in a limited capacity. This limited usage came about as there was no demand for the Internet in the private sector in 1986 when the Institute started to provide Internet services to universities. The government did not anticipate the growth in demand for the Internet from either the private sector or for general use. Local area networks at each campus were deployed almost simultaneously during the 1990s and early 2000s.

\subsection{Establishing information systems and archiving documents}

Scholarly communication could be said to be the most affected by the digitization trend. Almost all scholarly communication, previously reliant on printed articles and books, was transformed into digital format. Information systems were established to manage the digital archives, and meta-information for articles and books was also digitized.

In Japan, the Japan Information Center for Science and Technology had been providing science and technology journal articles on demand in printed form since 1957. This service became available online in 1976. At that time, there were only ten terminals available for obtaining article meta-information and abstracts. Even such a limited service required the creation of Japanese keywords and abstracts for each article. Technological developments to process Chinese characters were also needed as Asian language processing was not common at that time [12]. In parallel, bibliographic catalog systems were established in 1976. The development of these systems and the inputting of meta-information required vast amounts of time and energy [13]. Electronic libraries providing Japanese articles were also developed. 
Apart from scholarly communication, information systems for university business use, such as accounting and human resource management, were developed and introduced. Because of the specifics of the Japanese language and Japan's unique business practices, Japan had to develop its own information systems. What is more, because Japanese universities had practices very different than those of Japanese companies, special systems had to be developed for universities.

\subsection{Establishing policies for digital education}

Along with the provision of e-learning and online programs at universities came the need to establish policies for digital education. There has been some skepticism around e-learning, the criticism being that it did not provide the same level of interactivity as in face-to-face lectures. As such, the maximum number of credits that could be achieved through media was limited to 30 out of the 124 credits needed to graduate from an undergraduate program. This limit has now been increased to 60 credits, but no further. For distance education, it was required that a minimum of 30 credits be provided face to face, out of the total 124 credits. Now, all credits can be achieved through some sort of media [14].

Intellectual property law has also been amended to incorporate new digital needs. However, Japanese intellectual property law has not changed so far as to affect academic activities [15].

\section{Criticism Japanese Universities Face}

There is widespread concern in Japan that Japan is lagging behind other developed countries in terms of adapting to the digital age and transitioning to an information-based society. This is reflected in Japan's "Network Readiness Index" given in the Global Information Technology Report published annually by the World Economic Forum: Japan hovered around $20^{\text {th }}$ in the rankings until it finally reached the $10^{\text {th }}$ position in the 2015 report [16]. Even though Japan is now in the top ten for the overall index, it still ranks $15^{\text {th }}$ and $16^{\text {th }}$ for the economic and social impact sub-indices. More specifically, Japan ranks $24^{\text {th }}$ for "Impact of ICTs on business models," $33^{\text {rd }}$ for "Impact of ICTs on organizational models," $58^{\text {th }}$ for "Knowledge-intensive jobs," $28^{\text {th }}$ for "Impact of ICTs on access to basic services," $37^{\text {th }}$ for "Internet access in schools," and $37^{\text {th }}$ for "ICT use \& government efficiency" [17]. These rankings are by far unacceptable for Japan as it is one of the leading economic powers in the world. The Ministry of Internal Affairs and Communications (MIC) conducted an international comparative survey on the usage of ICT. Japan ranked $5^{\text {th }}$ among the seven countries surveyed. Especially in the fields of education/human resources and business management, Japan ranks at the bottom, with a deviation score of 35 [18]. These findings support the widespread concern that Japan is lagging behind other developed countries.

Japanese universities have been blamed for these deficiencies for several reasons.

\subsection{ICT services at minimum level}

The Ministry of Education, Culture, Sports, Science and Technology (MEXT) conducts a questionnaire survey on ICT usage in higher education every few years [19]. The results are compared with those for other countries. This section presents some of the results in the latest report for 2015.

Learning management systems (LMSs) are commonly used at universities in developed countries. Their penetration rate is roughly $60 \%$ in the U.S. and South Korea. In contrast, in 
Japan, the rates for national, public, and private universities are $80 \%, 40 \%$, and $20 \%$, respectively. Since private universities are the majority in Japanese higher education, the overall average is close to the private universities' level. In addition, even for the universities that have introduced LMSs, they are used for only $1-20 \%$ of all courses. This low level of LMS utilization means that Japan will have difficulties introducing personalized learning through adaptive technology which is attracting high expectations to assist students in learning but requires the use of LMSs.

The survey revealed that the ICT tools most widely introduced by Japanese universities are: syllabus systems (89\%), student information systems (63\%), and campus WiFi networks (79\%). The less widely introduced tools are OpenCourseWare $(\mathrm{OCW})$ or open educational resources (OERs) (11\%), digital textbooks (4\%), e-portfolio systems $(26 \%)$, and official social networking systems (28\%). In short, while an IT backbone has been deployed at a majority of Japanese universities, there has been less deployment of application tools for use in education. Application tool deployment in the U.S. was found to be much greater: contents/ learning management systems (90\%), digital textbooks and/or OERs (70-75\%), and "e-portfolio systems $(50 \%)$. A great gap is evident here in the adoption of ICT tools between those two countries.

The Japanese survey asked about barriers to introducing ICT tools. More than $95 \%$ of responding universities reported a lack of staff for creating digital contents and maintaining ICT systems, insufficient ICT skills for both academic and general staff, and a limited budget. More than $20 \%$ reported not having a support organization, not having a budget allocation, and not having support staff for online learning or ICT-assisted learning. It is clear that the lack of human and financial resources has been impeding the introduction and promotion of ICT tools for educational use.

Information systems for university business use, such as accounting and human resource management, were also reported to be unsophisticated and difficult to use. Since many schools have no budget or support staff allocated for these either, the information systems for business use are difficult to improve.

\subsection{Not meeting need of IT industry for skilled IT engineers}

Skilled IT engineers are in short supply in many countries of the world, and Japan is no exception. According to the "White Paper on IT Human Resources" published annually by the Information-Technology Promotion Agency, more than $90 \%$ of companies report a great lack $(24 \%)$ or lack $(67 \%)$ of IT human resources [20]. Japan is suffering more than other countries as it is an aging society. The Ministry of Economy, Trade and Industry (METI) forecasts that the number of people entering the IT industry will be less than the number of people leaving by 2019 and that the mean age of people in the industry will increase from 39 in 2015 to 41 by 2030. The shortage of human resources in the IT industry is estimated to increase from 170,000 in 2015 to 590,000 by 2030 [21].

The Japanese IT industry is particularly unattractive compared to those of other countries. METI conducted a comparative survey on IT human resources among eight countries (the U.S., Japan, South Korea, China, India, Vietnam, Thailand, and Indonesia), with 500 people in each country working in IT responding to the web survey. Only 34\% of the Japanese respondents agreed or strongly agreed that jobs related to IT were attractive whereas the percentage was around $80 \%$ for the other countries, except Korea with $50 \%$. Job satisfaction showed a similar result. Japan ranked especially low in terms of job achievement and salary/benefits. The average salary for U.S. respondents was almost double that for Japanese ones $(11,570,000$ vs. 
$5,980,000$ yen). The Japanese IT industry tends to follow the traditional seniority system in which one's salary rises in accordance with age whereas the average salary in the U.S. was highest for the respondents in their 30's and lower for those in their 40's and 50's. That is, the U.S. has a merit-based system that presents attractive job opportunities for young adults. The average job position of the Japanese respondents was the lowest among the eight surveyed countries. Only $38 \%$ of the Japanese IT workers were in managerial positions with responsibility for a business unit or division or were in an executive position even though the average length of employment was greater than that of all the other countries [22]. In contrast, $74 \%$ of the U.S. respondents were in managerial positions. In Japan, IT engineers are regarded as low wage workers rather than professional staff. There is a saying that IT-related jobs in Japan are 3K (kitsui (tough), kaerenai (not able to go home), kyuryo-ga-yasui (low salary)). It is no wonder that the IT industry has trouble attracting skilled young professionals.

Even though Japanese universities cannot be blamed for the unattractiveness of jobs in the Japanese IT industry, they are still criticized for not meeting the demand of the IT industry for skilled IT engineers. To meet this demand, several academic programs have been set up to produce IT engineers with practical skills or to produce human resources who can make business breakthroughs.

\subsection{Not producing startup companies}

In this age of drastic change, there is a strong need for startup companies that can make business breakthroughs on the strengths of new technologies and new business models. Established companies typically enter new markets only in an adaptive way; they are not adept at creating an entirely new market. Since a new market in the Fourth Industrial Revolution requires cutting-edge technologies and intelligent business operations, there are high expectations for universities to foster startups. For example, Google and Facebook were founded by graduate students at leading U.S. universities. The Japanese government and industry are demanding the same from Japanese universities.

The Japanese government set a target in 2001 to have 1000 startups from universities within three years - the so-called Hiranuma-Plan. It is set forth in the Basic Program for Science and Technology, which is laid out every five years and lays the foundation for science and technology policy in Japan. The target was met in 2004 thanks to the advocacy work of the government and the adoption of new regulations for startups. However, the government seems to have lost interest in university startups. The number established annually decreased dramatically after reaching a peak of 252 in 2005 (Figure 1) [23]. Since the number of university startups established per year is $400-500$ on average for the U.S., the gap between these two countries continues to widen [24]. The market shares of Japanese IT companies established after 1990 is $19 \%$ in terms of the number of companies and $9 \%$ in terms of the amount of sales. The numbers are $56 \%$ and $19 \%$ for the U.S. and $70 \%$ and $47 \%$ for the UK. In Japan, large established enterprises dominate the market, making it difficult to adapt to the new digital economy [25].

A questionnaire survey revealed that a downtown in the economy, difficulty raising funds and entering the market, a lack of success stories, high risk, little support from universities or the government, and occupation with education and research duties are among the leading reasons for the decrease in the number of new university startups [26]. In Japan, there have been almost no budget allocations for new policy agendas since the economic bubble burst in the early 1990s. The promotion of university startups is also failing with no additional investments. 


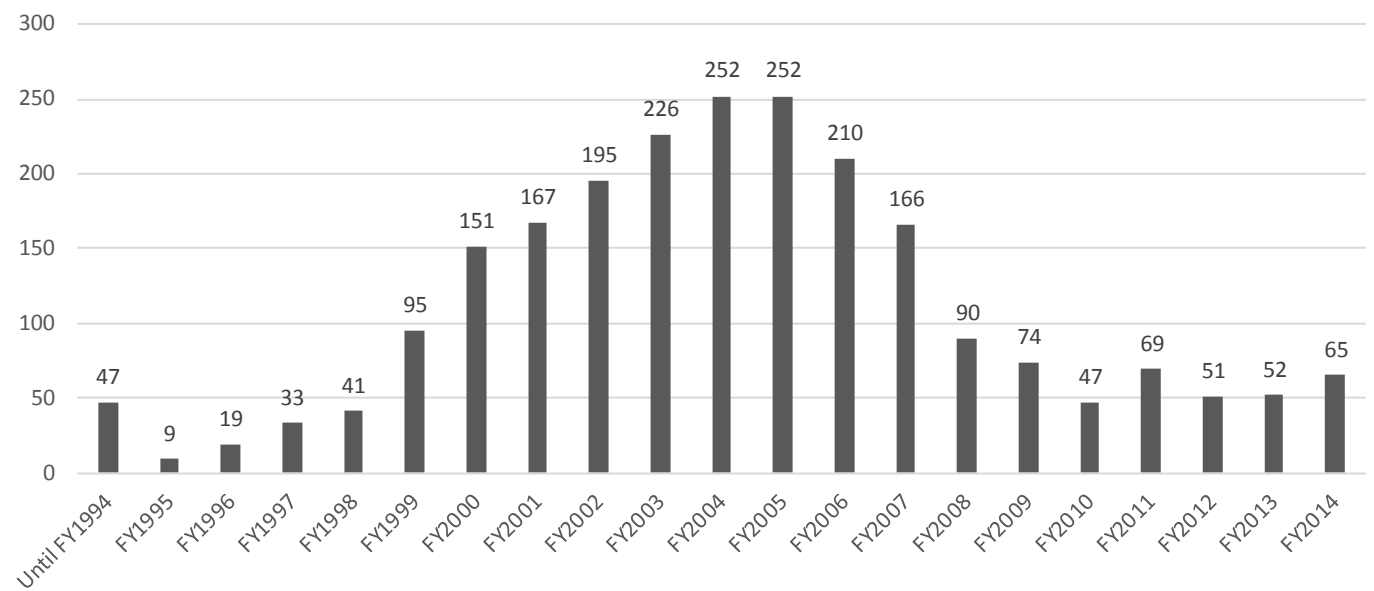

Figure 1. Number of university startups established

\section{Missteps in transition to information-based society}

What is the reason for the deficiencies of the IT industry in Japan? Japan has not overlooked the importance of becoming an information-based society. In fact, Japan was one of the first countries to address this need as a leader in electronics. Nevertheless, at the turn of the century, Japan came to realize that the country was lagging in terms of IT. This led to the establishment of the IT Strategy Headquarter under the Cabinet. The headquarter drafts the "e-Japan Strategy" and implements and monitors the related policy measures on an annual basis. Broadband networks, such as the fiber-to-the-home (FTTH) network, were successfully deployed due to these measures. However, the software and applications industry is still struggling to succeed in international markets.

This section discusses the issues facing Japan in its efforts to transition to an information-based society. It starts by examining the measures taken by universities at the beginning of the digital age, as described in section 2, and then considers the criticism Japanese universities has received, as described in section 3 .

\subsection{Misinterpreting the real value of IT: computation vs. communication}

As described in section 2.1, Japan started early on to set up computer science departments to educate computer engineers. This effort was accelerated due to the strong demands of the computer industry in the 1970s and 1980s. The demands were especially high for engineers who could work on research and development (R\&D) of computers, smart electronic devices, and information systems for business use. Even the information literacy education for general students was based around the usage of computers and computer programming, as seen in section 2.2. In short, the academic programs were focused on developing human resources in hard sciences strong in computational needs.

In contrast, the business targets of successful IT companies such as Google, Amazon, Facebook, and LinkedIn are formed around human communications and information gathering 
rather than meeting computational demands. Google invented a search engine that puts the most relevant information for the user at the top. Amazon invented a 1-click ordering, recommendation engine and gift certificates that take it beyond simply being an e-commerce site. Facebook, Twitter, and LinkedIn are social networking services that meet the human desire to communicate. Even big data analysis, which has been attracting much attention recently, is aimed at meeting the human desire for relevant information, especially in shopping.

Kokuryo pointed out that Japan failed to understand that computers were becoming communication tools rather than computational tools [27]. This is a very revealing statement. Electronic contents only become information when there is human intervention. Information technology needs to interact with people in order to convey meaningful information.

Since most computer science departments are still in the school of engineering, they attract students mainly interested in hard sciences and not in human communication and interactions. Since the faculty members are generally graduates of similar departments in the same discipline, an ecosystem with people interested in hard sciences has formed in those departments, making it difficult to pursue an alternate path to human-related research topics. The IT industry reflects this problem as their IT employees came from those same departments.

Even the way ICT is used in classrooms is preventing Japan from seeing ICT tools as communication devices. Toyofuku pointed out that since classes are designed to fulfill the goals of the teacher, there is a belief that ICT tools should be used exactly as directed by the teacher [28]. ICT tools are usually used to complete certain tasks given by the teacher, such as composing a document or searching for particular information. In general, teachers avoid using ICT tools to share information with and communicate with students. With the widespread use of smartphones and similar devices, there is hope that this is going to change as students are using ICT tools to communicate outside the classroom.

\subsection{Neglecting importance of professional IT support staff}

As seen in section 3.1, a minimum level of ICT services is generally provided at Japanese universities. Only $49 \%$ of universities report having a helpdesk to handle network trouble shooting and Internet security. Support for academic activities in education and research is rarely available. The reasons given for this are, as mentioned, a lack of staff for creating digital contents and maintaining ICT systems, insufficient ICT skills for both academic and general staff, and a limited budget. There is a lack of understanding regarding the importance of a professional IT support staff. In the U.S., three-quarters of the universities provide, on average, 80 hours of helpdesk support a week. This support goes beyond maintaining the IT infrastructure and troubleshooting information systems. It extends to academic activities such as assisting faculty members in using ICT tools for education and research. There are training courses and one-to-one consultations available. In large public universities, the IT centers are staffed with more than 100 people. There is even a saying that secretaries are laid off and IT staff is hired instead in the digital age.

ICT should have been seen as human services rather than physical goods. As described in section 2, efforts to adapt to the digital age in Japan were mainly related to educating computer engineers and deploying IT infrastructure. There was the assumption that high-tech IT goods lead directly to marketability. However, the adoption of a new technology by society depends on the efforts of facilitators. Facilitators are needed to advocate for the new technology and assist people in using it. Especially in the case of ICT, which is not a physical good but a virtual system, the functions performed by a human facilitator are essential. Japan overlooked the fact that the transition to an information-based society requires human support as well as key 
technologies.

The reason for the rich support at U.S. universities and at those in other Western countries is due to the demand of the students and to having a younger generation as users of information services. In many countries, wireless networks and information systems such as LMSs are widespread already at the high school level. When students enroll in universities, they demand the same level of support. In Western countries, it is common for graduate students to give lectures, lead classes, and give final grades. Close to thousand students can comprise one class, meaning that ICT tools such as an LMS are needed to handle the class. Since graduate students typically adapt to new technologies quite easily, ICT tools rapidly come into use. In Japan, only qualified professors are allowed to give lectures and lead a class. The number of students in a class can range from several dozens to two hundred. The professors are of course older than graduate students and thus more reluctant to use new technologies. Moreover, the class size does not demand the use of such technology.

\subsection{Too much emphasis on creating digital contents}

Another reason for Japan lagging behind in transitioning to an information-based society is that Japan has put too much emphasis in creating digital contents rather than developing an information system to host those contents.

For example, a great amount of time and effort went into creating the catalog, keywords, abstracts, and other metadata in digital format for the Japanese journal article database and bibliographic catalog system described in section 2.4. Even though the development of the information system also needed elaboration, a much greater amount of time and effort went into creating the contents. Another example is the "e-Japan Priority Policy Program," which is published annually under the "e-Japan Strategy." It includes many measures for creating digital contents in various fields and only a few for developing an information system or for determining what kinds of information systems will be needed in the future.

It seems as though Japan misinterpreted "information-based society" as a society full of digital contents. Certainly, Japan had to work on preparing digital contents in Japanese as its society is based on the Japanese language. However, as the information-based society materializes, we see that creating a new way to link information and people to increase communication and exchanges among people is by far more important than creating digital contents or implementing high-tech computer processing. Digital contents are naturally created as people spend more time in cyberspace.

\subsection{Avoidance of ICT}

There is also a culture of avoiding ICT in Japan. ICT-related policy papers over the last two decades consistently mention the "light and dark side" of using of ICT. There is a notion that ICT should be introduced carefully to avoid the dark side.

This warning is especially strong for policy measures related to elementary and secondary schools. The Ad Hoc Council on Education set up by Prime Minister Nakasone (1984-87) was very influential in reshaping the elementary and secondary school systems in Japan. Its main goal was to revive Japanese schooling, which was considered broken due to school violence and excessive competition on entrance exams. In addition, the Council addressed the transition to an information-based society, the challenges of an aging society, and the trend toward globalization. It discussed how school systems should respond to the structural changes in industry and employment. Nonetheless, its policy measures were not aimed at introducing ICT into education in a straight-forward manner. Rather, the "light and dark side" of ICT was 
repeatedly mentioned. The guidelines created for introducing ICT into the school system mainly follow the recommendations of the Council and include a whole chapter devoted to the "light and dark side" of ICT.

Toyofuku observed that there is a widespread belief that addiction to and prolonged usage of ICT will harm the human nature of students. ICT thus has to be restricted by adults as it will affect the health and school achievements of students. This includes forbidding students to bring mobile phones to school and to use them at night. Such measures also prevent the use of e-mail for communication between the school and parents and restrict communication between students and parents via electronic services [28].

The beliefs that ICT will harm the human nature of students and that deep learning can only be achieved through thorough reflection are also evident in higher education. The positive side of ICT, that work can be performed more efficiently and that it enables communication beyond time and space restrictions, is not acknowledged as much. Even though people have come to appreciate the benefits of ICT tools, they are still viewed as being in the same dimension as basic infrastructures such as electricity and telephony. There seems to be minimal understanding that ICT can lead to a better life.

\subsection{Japanese language environment}

Although Japan cannot be blamed for having Japanese language environment, it is obvious that this environment has been a great barrier to transitioning to an information-based society.

Japan is the only country where Japanese is the main language and where Japanese characters, which is also making use of Chinese characters, are used. Since ICT inherently requires the use of language and characters, the hurdle created by this characteristic is unavoidable. Almost every information system had to be produced in Japanese as well as in English. Since Japan was one of the leaders in electronics, it developed many systems on its own without copying the system from other developed countries and translating it into Japanese. When Japan developed information systems on its own in Japanese, it naturally developed systems that fit Japan's societal and cultural needs. They suited Japanese people but were difficult to market outside Japan. This became known as the "Galápagos syndrome," referring to isolated development in Japan apart from the global trend. Mobile phones in Japan are examples of this. The Japanese IT industry expended much time and great effort in developing goods that are marketable only in Japan.

The Japanese keyboard system alone required tremendous R\&D to be able to input Japanese characters, display them on a screen, print them out, and make them searchable on the Internet. The Western alphabet has only 26 characters whereas the Japanese language uses three different sets of characters amounting to several thousands of characters as Chinese characters are also used. Creating a Japanese information processing system was not enough. Digital contents in the Japanese language needed to be created and accumulated as well. Since the input of Japanese letters through the special keyboard system required professional skill, it took some time until a substantial amount of digital contents could be accumulated. Japanese companies still required typists until the beginning of the 1990s.

It took almost two decades before everyday people could type Japanese letters using the keyboard system. Even today, most people older than 70 do not have this ability. They thus miss out on the use of e-mail and the Internet. The penetration of mobile phones was the major factor in the younger generation being able to type Japanese letters electronically. It was not until 2008, when the penetration rate of mobile phones crossed the $80 \%$ line that the use of e-mail and the Internet expanded dramatically. Western countries thus had a tremendous 
advantage due to having only 26 letters in general and due to mechanical typewriters being in common use since the beginning of the $20^{\text {th }}$ century.

\section{Measures to be taken in Japan to transition to information-based society}

The missteps taken in transitioning to an information-based society, as described in section 4 , show that Japanese universities were not to blame for most of the problems. It was not their fault that Japan misunderstood that the real value of IT was not computer processing but rather communicating. Japanese universities were not responsible for too much emphasis being placed on creating digital contents rather than on developing systems to enhance information exchange and communication. Universities appreciated the need for professional IT support staff but were hamstrung by severe budget constraints.

Certainly, universities have been providing academic programs and conducting R\&D in computer sciences and have been in a position to point out the missteps as they became aware of them. However, the misunderstanding of the meaning of an information-based society was common across all areas in Japan including universities, industry, and government. Criticism has been directed towards Japanese universities because there is no clear target for the blame. The easiest way is to accuse the universities as they are responsible for nurturing human resources and conducting R\&D in the new field and are the closest to the innovations. Since universities are in a period of drastic reforms, such claims are easy to make.

The issues described in section 4 were pointed out by various people on various occasions. The real issue is that there is no one stepping up to tackle these issues in a serious manner. Arguments such as "Japan is not good at developing systems" are repeatedly heard. However, if people know where the problem is, they should be able to solve it. If Japan is really not good at developing systems, experts from overseas could be recruited to help.

The fact that the government seems to have lost interest in working on the issues related to ICT is also a concern. While there are several policy measures targeting ICT-related issues, such as including more women and more seniors in the IT workforce and developing IT systems for emergency response and agriculture, there are no policy measures targeting the fundamental issues related to transitioning to an information-based society, as described in section 4.

Most of the issues have not been carefully thought through because of budget limitations. Japanese culture, in general, is frequently blamed. Startups are not succeeding because "Japan has no culture of giving," "there is limited venture capital in Japan," "startups don't work in Japanese culture," and so on. Governments could have established programs dictating that a certain proportion of governmental spending must be allocated to startups, thereby providing the necessary funds, providing employment opportunities, and developing innovative technologies and services all at the same time. Policymakers often talk about the importance of a "career path" if IT-related jobs are to become attractive. However, the hiring of staff is left entirely to companies and universities. These actors are unable to hire people on the basis of job position stability. They have to prioritize efficiency, which results in low wages and poor working conditions.

So what should Japanese universities do? Is it OK to stand aside, doing nothing, as it is not their business? At this moment, all the stakeholders (government, industry, and society) seem to have left the arena. Even universities are avoiding acting on the issues as they are suffering 
from long-lasting university reforms and tight budgets. This will only worsen the situation. Getting away from this stagnant situation requires innovation. In this milieu, it remains up to universities to drive the changes needed. Universities are in the best position to make breakthroughs in their role as academic institutions creating new knowledge and developing human resources.

Fortunately, digital natives are entering the workforce. Most of the issues described in section 4 are not relevant to this younger generation. They look upon ICT tools as communication tools. They have lived in the cyber-physical world their whole life and have no hesitation in using ICT tools. They know how to navigate cyberspace and how to innovate. Creating applications has never been easier. The key is to let the younger generation take the lead. In Japan, the seniority system is king-younger employees are expected to follow the same paths taken by the senior employees. However, the ideas of younger employees are more likely to lead to a breakthrough than those of the older employees, especially when it comes to transitioning to an information-based society.

Universities are places where ideas are born and students are trained to change the world. Universities are thus the most promising change agent, speeding up the transition to an information-based society in Japan.

\section{Acknowledgments}

This work was supported by JSPS KAKENHI Grant Number 22653097 "Academic Management in Top Research Universities," 22653097 "The Impact of MOOCs on Higher Education," and 15K13175 "The Impact of US Mega-Foundations on Higher Education Policy Formation."

\section{References}

[1] J. Surowiecki, The Wisdom of Crowds, Doubleday, 2004, p. 336.

[2] P. Gourdain, F. O'Kelly, et al., La Révolution Wikipédia: Les encyclopédies vont-elles mourir? Mille et une Nuits, 2007, p. 144.

[3] D. Bok, Universities in the Marketplace: The Commercialization of Higher Education, Princeton University Press, 2004, p. 256.

[4] M. Trow, Twentieth-Century Higher Education: Elite to Mass to Universal, Johns Hopkins University Press, 2010, p. 640.

[5] Y. Masuda, The Information Society as Post-Industrial Society, Transaction Publishers, 1980, p. 178.

[6] D. Bell, The Coming of Post-Industrial Society: A Venture in Social Forecasting, Basic Books, 1976, p. 616.

[7] A. Toffler, The Third Wave, Bantam, 1984, p. 560.

[8] Council on Information Processing Education, Ministry of Education, Japan, "Quantitative Basic Data for Raising Information Engineers,” 1971. In Japanese, 
Jyoho-shori-gijyutsusha Yosei-keikaku-no Teiryoteki-kiso.

[9] National Forum On Information Literacy, "What is NFIL?," NFIL website, http://infolit.org/about-the-nfil/what-is-the-nfil/.

[10] National Information Processing Center (NIPC), "About the Research Meeting on Information (Processing) Education.” 2008. In Japanese, Jyoho-shori-kyoiku Kenkyu-shukai ni-tsuite.

[11] A. Sugie and M. Ohsaki, "Information Literacy Education in the Year 2006 Problem," Nagoya Bunri University Kiyo, vol.7, 2007 , p29-32;

http://www.nagoya-bunri.ac.jp/information/memoir/files/2007_05.pdf

[12] Y. Otani, "Development for Information Retrieval System in Japan Information Center for Science and Technology (JICST)," Kokubun Mejiro, vol. 53, 2014, p.33-42.

[13] K. Konishi, "The History of National Institute of Informatics-the Activity for the Constitution of Infrastructure of Scholarly Information-," proceedings at a lecture talk, 2005; http://www.sousei.gscc.osaka-cu.ac.jp/ws/wspdf/media/m050113.pdf

[14] Science and Technology \& Academic Council, "Midterm Report on the Deployment of Computers and Network for Academic Information Infrastructure," 2005. In Japanese, Gakujyutsu-jyoho-kiban toshite-no Computer oyobi Network no Kongo-no Seibi-no-Arikata ni-tsuite.

[15] Subcommittee on Copyright Issues, Council for Cultural Affairs, "Issues to be discussed in the sixteenth Subcommittee on Copyright Issues, Council for Cultural Affairs," 2016. In Japanese, Dai-16-ki Bunka-Shingikai Chosakuken-Bunkakai Housei-Kihon-mondai Sho-iinnkai ni okeru Toumen-no-Knetou-Kadai oyobi Kentou-no-Susumekata nitsuite (an); http://www.bunka.go.jp/seisaku/bunkashingikai/chosakuken/hoki/h28_01/pdf/shiryo_3.pd $\mathrm{f}$

[16] Ministry of Internal Affairs and Communications, "Information and Communications in Japan 2009,” 2009; http://www8.cao.go.jp/cstp/tyousakai/innovation/ict/2kai/siryo2.pdf

[17] World Economic Forum, "The Global Information Technology Report 2016," 2016, p. 291; http://www3.weforum.org/docs/GITR2016/WEF_GITR_Full_Report.pdf

[18] Ministry of Internal Affairs and Communications, "International ICT-related trends and ICT-Usage Survey,” 2009. In Japanese, ICT-kanren-Doukou no Kokusai-Hikaku oyobi Kokunaigai-no ICT-Rikatsuyou Senshin-Jirei-Chosa;

http://www.soumu.go.jp/johotsusintokei/linkdata/h21_03_houkoku.pdf

[19] Kyoto University, "Study on ICT Usage at Japanese Higher Education Institutions," 2014, p. 345. In Japanese, Heisei-25-nenndo Monbu-Kagaku-Sho Sendo-teki Daigaku-Kaikaku Suishin Itaku-Jigyo: Koutou-Kyouikukikan-tou-niokeru ICT-no-Ri-Katsyo-ni-kansuru Chosa-Kenkyu (Itaku-Gyomu Seika-Houkokusho; http://www.mext.go.jp/component/a_menu/education/detail/_icsFiles/afieldfile/2014/05/ 19/1347641_05.pdf 
[20] Information-Technology Promotion Agency, "White Paper on IT Human Resources 2016," 2016, p. 303. In Japanese, IT-Jinzai-Hakusho;

https://www.ipa.go.jp/jinzai/jigyou/about.html

[21] Ministry of Economy, Trade and Industry, "Survey on the Latest Trends and Future Forecast of IT Human Resources," 2016. In Japanese, IT-Jinzai no Saishin-Doko to Shorai-Suikei ni kansuru Chosa-kekka; http://www.meti.go.jp/policy/it_policy/jinzai/27FY_report.html

[22] Ministry of Economy, Trade and Industry, "International Comparative Study on IT Human Resources,” 2016. In Japanese, IT-Jinzai ni kansuru Kakkoku-Hikaku-Chosa Kekka-Houkokusho; http://www.meti.go.jp/policy/it_policy/jinzai/27FY/ITjinzai_global.pdf

[23] Ministry of Education, Culture, Sports, Science and Technology, "University-Industry Linkage F.Y. 2014,"2015. In Japanese, Heisei-26-nendo Daigaku-to ni-okeru Sangaku-Renkei-to Jisshi-Jyoukyou nitsuite; http://www.mext.go.jp/component/a_menu/science/detail/_icsFiles/afieldfile/2015/12/25/ 1365509_2.pdf

[24] S. Matsuda, "Exploring the Possibility of Start-ups started by Universities-Reality, Issue, and Strategy," Journal of Industry-Academia-Government Linkage, vol.4, 2014. In Japanese, Daigaku-hatsu-Benchaa no Kanousei wo Hikidasu-Sono Genjyo, Kadai, Senryaku;

https://sangakukan.jp/journal/journal_contents/2014/04/articles/1404-02-1/1404-02-1_arti cle.html

[25] Ministry of Internal Affairs and Communications, "Structural Change and Future Prospects of Global ICT Industry,"2015. In Japanese, Global-ICT-Sangyo no Kozo-Henka oyobi Shorai-Tenbou-tou ni kansuru Chosa-Kenkyu; http://www.soumu.go.jp/johotsusintokei/linkdata/h27_02_houkoku.pdf

[26] National Institute of Science and Technology Policy, "Academic Start-ups Survey 2010: A questionnaire survey of universities and research institutions,"2011, p. 164. In Japanese, Daigaku-tou-Bencha-Chosa 2010-Daigaku-tou-heno Anketo-ni-motozuku Bencha-Seturitsu-Jyokyo to Bencha-Shien Sangaku-renkei ni-kansuru Ishiki; http://data.nistep.go.jp/dspace/handle/11035/875

[27] J. Kokuryo, "Chapter 5 Information and Communication: Japan which failed to network," Policy Research Institute, Ministry of Finance, The Efficiency of Japan's Economy and Ways to Recover, 2000;

https://www.mof.go.jp/pri/research/conference/zk030/zk030e.pdf

[28] S. Toyofuku, "Use of ICT in Primary and Secondary Education : 1. Why ICT Use in Japanese Schools is Retarded-From Policy Conversion to Learner-centered Use of ICT," JPSJ Magazine “Joho Shori,” Vol.56(4), 2015, p.316-321; https://www.ipsj.or.jp/magazine/9faeag000000jvu7-att/5604-01.pdf 